\title{
Mapas desejantes: uma agenda para a Cartografia Geográfica
}

Gisele Girardi*

Resumo: Este artigo discute como imagens cartográficas disseminadas na vida social produzem mundos e capturam-nos para eles; em outras palavras, desejam-nos. Para isso, foram utilizadas quatro cenas, extraídas de situações da vida cotidiana da própria autora. Em todas as cenas, mapas estiveram presentes. O significado da produção cartográfica nestes contextos específicos, bem como a sua força na criação da imagem de um mundo - na produção de um mundo - foi discutido, assim como o desdobramento dessa reflexão na Geografia, incluindo seu ensino, considerando este um tema importante na agenda da Cartografia Geográfica.

Palavras-chave: Cartografia Geográfica; imagem cartográfica; pensamento sobre o espaço.

\section{Desiring maps: an important issue for geographic cartography}

Abstract: This paper brings a discussion on how cartographic images disseminated in social life produce worlds and captures us for them or, in others words, they desire us. Four scenes from the author's daily-life situations were used. In all of scenes, maps were present. The meaning of the cartographic production in these specific contexts, as well as their strength in the creation of an image of the world - in the production of a world - was studied. The consequences of this reflection in Geography, including geography teaching, were discussed, considering that this is an important issue for geographic cartography.

Key words: geographic cartography; cartographic image; thinking about space.

\section{Introdução}

Mapa é imagem. Tangível, virtual ou mental evoca, sempre, a imagem de um território. A noção de território aqui é a mais ampla possível, podendo referir-se tanto aos recortes de natureza político-administrativa/jurídica - os territórios da oficialidade, limitados por fronteiras fixas - como ao conjunto de elementos articulados em dimensões culturais e simbólicas - as territorialidades (Costa, 2006).

* Professora do Departamento de Geografia do Centro de Ciências Humanas e Naturais da Universidade Federal do Espírito Santo, Brasil.g.girardi@uol.com.br 
Para a ciência geográfica, o mapa é um objeto-símbolo. Seu modo específico de imagear as feições da superfície terrestre, sejam as naturais sejam as transformadas pela ação humana, compôs, de início, o arcabouço de conhecimentos e de condiçóes materiais para a existência da Geografia como campo de conhecimento científico (Moraes, 1997). Atua, para esta ciência, como um mito fundador, não sendo incomum que se recorra à etimologia geo+graphein (terra+desenho, desenho da terra, logo, mapa) para justificar a força desse objeto na produção científica em Geografia.

Podemos dizer que o estatuto imagético dos mapas, seu poder de fixação documental dos atributos de um pedaço de mundo do qual a Geografia fala, transforma-o em legitimador do fazer geográfico, transferindo sua força de símbolo também para o ensino de Geografia.

Como artifício de registro de espacialidades para fins diversos, os mapas sempre estiveram presentes nas sociedades humanas. Concordamos com Harley quando atribui aos mapas a função de um registro gráfico que "facilita a compreensão espacial de objetos, conceitos, condiçōes, processos e fatos do mundo humano" (Harley, 1991, p. 7). Essa matriz de pensamento acerca do mapa é que nos habilita a pensar nos significados desse objeto-imagem na construção de conhecimentos geográficos para além do campo formal de atuação da ciência geográfica - seu ensino, sua pesquisa, sua aplicação - e a buscar potencialidades dialógicas entre esses campos.

Moreira (2004) instiga-nos com a idéia do atual distanciamento entre a geografia real ("da realidade que existe fora de nós") e a geografia teórica ("da leitura desse real") e reputa à perda da personalidade lingüística desta última da cartografia como mediadora do pensamento - grande parte da responsabilidade por esse distanciamento.

Tomando emprestados seus termos, dizemos que a geografia real deseja mapas e é desejada por eles, ao passo que na geografia teórica se escancara a crise da relação Geografia-Cartografia, que tem sido estudada por vários pesquisadores em vários de seus aspectos ${ }^{1}$. A simples existência dessa pauta já representa um imenso avanço, mesmo sem significar, necessariamente, avanços técnicos e metodológicos de relevo na direção apontada pela crítica geográfica.

Assim, arrisco-me, como provocação, a analisar esses mapas da geografia real por meio do desejo: o desejo do cartógrafo, o desejo do usuário e as possibilidades de o mapa, ele mesmo, ser um objeto desejante, contaminado pelos dois últimos, mas, principalmente, contaminado pelo jogo de relações sociais

I. Cito como exemplares, dentre vários outros, os trabalhos de Jeremy W. Crampton e John Krygier, "Uma introdução à cartografia crítica", e de Jacques Lévy, "Uma virada cartográfica?", traduções publicadas em Acselrad (2008). Para a situação brasileira, ver Girardi (2004). 
que, em certo momento e em certas circunstâncias, valoriza-o e significa-o para além dos desejos de seus criadores e usuários.

Para conduzir as reflexões que pretendo desenvolver neste texto, trago cenas de situações vividas, nas quais mapas estiveram presentes. Apesar de mapas serem o ponto de convergência da minha atuação profissional - como docente, pesquisadora, autora - estas cenas extrapolam o ambiente do estritamente profissional e foram escolhidas justamente porque trazem algo de generalizável, permitindo reflexões sobre mapas em dimensões diversas da vida social.

\section{Cenas}

Cena I. Mapa das artes, na metrópole paulistana

Programa de família: Museu da Língua Portuguesa, na capital paulista. $\mathrm{Na}$ saída, próximo às catracas, um pequeno móvel, com tampo de vidro e um vão sob este. No vão, uma pilha de mapas dobrados. "Mapa das artes - São Paulo" era seu nome. Edição número 41, janeiro e fevereiro de 2009. Ao funcionário que circulava próximo, perguntei: "posso pegar?" Acenou positivamente com a cabeça e saí de lá com o meu mapa. Observei que quase ninguém parava para pegar ou, como eu havia feito, perguntar se podia pegar um exemplar. Talvez porque o vidro e o fato de estarmos no ambiente do museu metamorfoseassem o mapa numa peça deste. "Não toque nos vidros" são dizeres recorrentes em um museu...

Na primeira oportunidade, saquei meu mapa da bolsa e comecei a desdobrálo. Um singelo volume de aproximadamente $10 \mathrm{~cm}$ por $20 \mathrm{~cm}$ transformou-se numa folha de $90 \mathrm{~cm}$ por $60 \mathrm{~cm}$. De um lado, um mapa do tipo guia de ruas, abrangendo aproximadamente o centro expandido ${ }^{2}$ de São Paulo, emoldurado por propagandas de artigos de arte (tintas, molduras e que tais). Do outro lado, com semelhante moldura, uma lista-legenda com cores e números identificando os locais da arte na cidade: museus e espaços públicos; galerias e escritórios de arte; espaços institucionais; ateliês e serviços. Cerca de cem referências, com endereço, descrição da exposição ou do acervo, ou do serviço.

Esse mapa revelou-me (e guiou-me para) um local que desconhecia: uma pequena galeria privada com uma exposição de colagens feitas sobre intervenções em mapas.

\section{Cena 2. O mapa e o GPS do taxista de São Caetano do Sul}

Tendo que me deslocar do centro da cidade de São Caetano do Sul até a casa onde me hospedara, tomei um táxi. Era uma distância de não mais que três

2. Barra Funda e Santa Cecília ao norte; Braz e Ipiranga ao Leste; Vila Mariana, Moema e Itaim Bibi ao Sul; Morumbi e Alto de Pinheiros a Oeste. 
quilômetros, que habitualmente eu cumpria a pé, mas, naquele momento, circunstâncias particulares me impediam de fazê-lo. Ao entrar no táxi, perguntei se o motorista conhecia a avenida à qual me destinava. Pergunta protocolar, pois não só a avenida era bastante conhecida no local como, no ponto onde estávamos, qualquer caminho desembocaria nela. Também, protocolarmente, ele me respondeu que conhecia. Mesmo assim, ligou seu GPS de bordo, digitou o nome da avenida e, a todo tempo, olhava para o dinâmico mapa que o aparelho ia mostrando.

Pensei em algumas hipóteses acerca do comportamento do taxista: queria ele mostrar que seu veículo era hi-tech e assim conquistar a clientela? Seria ele novo no ponto e teria dúvidas acerca do trajeto? De onde, afinal, teria surgido essa necessidade do uso do GPS para aquele breve trajeto? Ao final da corrida, que não durou mais que dez minutos, perguntei-lhe por que tinha ligado o GPS se sabia o trajeto. Singelamente me respondeu que realmente ele não teria a necessidade de ter ligado o aparelho para aquela viagem, mas os clientes normalmente sentiam-se mais seguros em relação ao trabalho do motorista quando o aparelho estava ligado, ou seja, não desconfiavam de que o motorista estivesse aumentando o trajeto ou desviando do caminho: o mapa servia para mostrar o caminho e também para provar que o motorista era honesto.

\section{Cena 3. Mapas do Sossego, interior do Espírito Santo}

Há alguns anos participo de um grupo de pesquisa sobre gestão de recursos hídricos que tem como área-piloto uma microbacia no interior do Espírito Santo denominada Córrego do Sossego. Uma cópia da carta topográfica correspondente à área da microbacia sempre nos acompanhava em campo. Ela sempre foi o mediador das nossas observações, medições, anotações. Nosso porto seguro, posto que não tínhamos referências de vida naquele lugar. As localidades denominadas no mapa são Alto Bananal, Alto Sossego, Sossego, Santa Helena e Baixo Sossego. Tínhamos dificuldades em absorver informações da população local, pois nos indicavam "os alemães lá de cima", "lá nos Meneguel", "no Rizzi", etc. Certa vez, conversando com uma moradora local, expusemos nossa dificuldade em situar certos locais mencionados pela comunidade, ao que ela nos explicou: "nós chamamos assim os lugares, mas sabemos que não é o certo. O certo é como o correio chama". O "como o correio chama" é o que consta na carta topográfica.

Cena 4. Mapa de atlas, numa escola do interior de Minas Gerais

Certa vez, em um evento, veio falar comigo a professora de uma escola do interior de Minas Gerais, que se identificou como usuária de um material 
didático que eu havia co-autorado ${ }^{3}$, mas que não sabia o que fazer, quando os alunos perguntavam por que a cidade em que eles moravam não estava no mapa. Pedi-lhe para explicar às crianças que o mapa da Regiáo Sudeste, que eles consultavam, precisou ser muito reduzido para caber naquela folha de papel, na página do Atlas; que por isso nós tivemos de fazer uma seleção, pois não caberia tudo; e usamos alguns critérios para selecionar as cidades que entrariam no mapa, como tamanho da população, existência de patrimônios históricos e outros. E também lhe pedi para dizer às crianças que era para marcarem com uma caneta e com uma letra bem caprichada a cidade deles no mapa. De imediato, a professora falou: "não podemos fazer isso, os exemplares são da biblioteca e a diretora nos mataria!".

Com essas cenas, espero ter criado em meu leitor imagens da vida cotidiana perpassada por mapas. $\mathrm{O}$ que essas cenas trazem como reflexão sobre os mapas na vida social? Que poderes têm essas imagens na compreensão do mundo, por pessoas ou grupos sociais tão distintos?

\section{Do desejo do cartógrafo ao mapa desejante}

O processo de transmissão de informações por meio de mapas foi desenhado por Kolacny em 1967 e permanece válido como modelo analítico até os dias atuais. Ainda que vários autores indiquem a visualização cartográfica ${ }^{4}$ como o paradigma atual, a comunicação cartográfica permanece como foco da Cartografia, atuando a partir do momento em que, pelo processo de visualização, chegou-se a um resultado a ser publicizado.

Em seu modelo de transmissão da informação cartográfica, Kolacny identifica como o início e o fim do processo a Realidade, ou melhor, a intersecção das esferas do que chama "Realidade do Cartógrafo" e "Realidade do Usuário do Mapa" (Figura 1). A eficácia do mapa relaciona-se diretamente com o tamanho da intersecção dessas esferas. A busca pela máxima intersecção seria, então, o desejo do cartógrafo. Para alcançá-la todas as dimensóes que afetam tanto o cartógrafo como o usuário do mapa devem ser levadas em consideração. Trocando em miúdos, quanto mais o cartógrafo puder conhecer do perfil, das condições e das necessidades do usuário do mapa, maiores possibilidades do uso da linguagem cartográfica para adequação a esse usuário.

3. Girardi, G.; Rosa, Jussara Vaz. Novo atlas geográfico do estudante. São Paulo: FTD, 2005.

4. Modalidade de visualização científica caracterizada por processos de interação do usuário com mapas, mediados pelas geotecnologias, visando novas descobertas. 


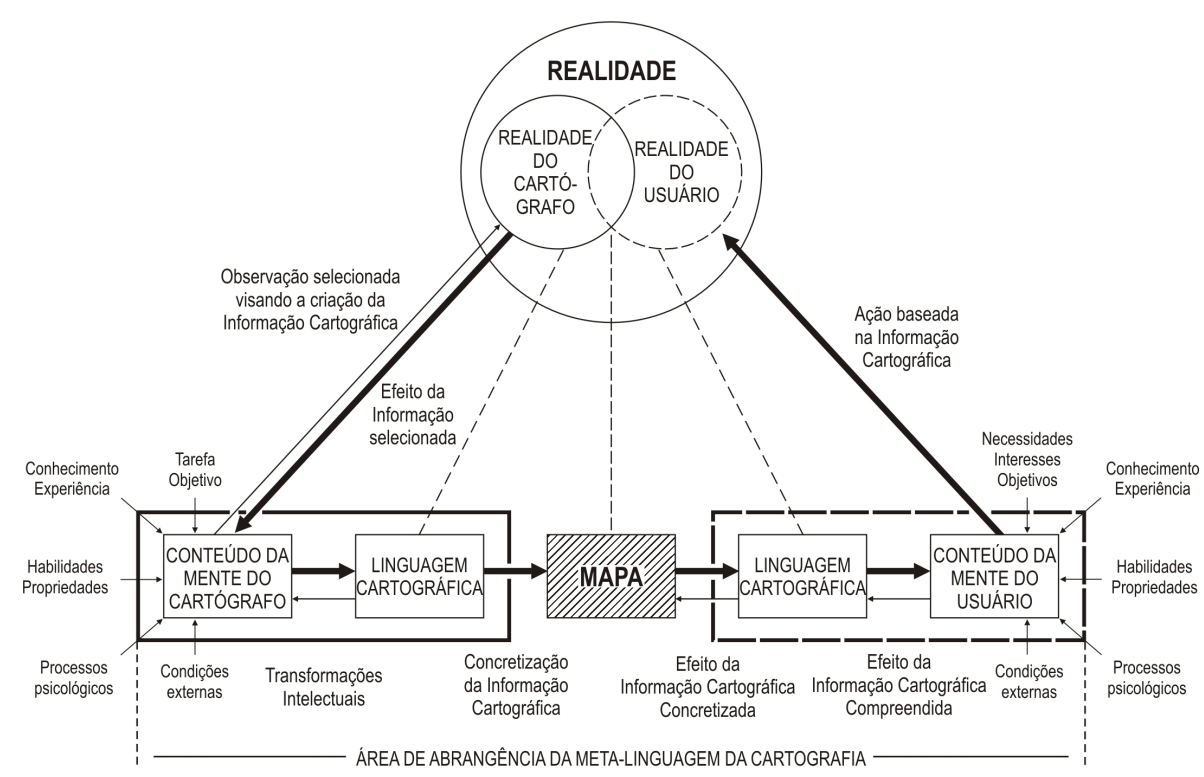

Figura I - Comunicação da informação cartográfica. Kolácny, I 967 (Cf: Kolácny, I 977)

O modelo de Kolácny, ao trazer as condições do usuário como componente do processo comunicativo, alavancou uma série de investigações acerca dos modos como a informação é recebida pelo usuário do mapa. Ampliando o acesso do usuário à informação mapeada, amplia-se o desejo do usuário por mapas como fonte de conhecimentos.

Duas considerações são de interesse para o que queremos discutir aqui. A primeira delas é que a "customização" do mapa para um público-alvo determinado não elimina as incertezas da transmissão da informação, o que já era, inclusive, previsto no modelo. Mais do que isso, mesmo elegendo um públicoalvo e adequando a ele raciocínios de generalização, escolhas e linguagem, o mapa, ao ser finalizado, transforma-se em objeto da cultura material e chega pleno em contextos variáveis, disponível para significaçôes diversas.

A outra é que o componente "real e objetivo" do mapa é somente a posição, absoluta ou relativa, dos objetos, fatos ou fenômenos mapeados. A existência de referenciais reconhecidos empresta sua "realidade" a tudo o mais que tenha existência no mapa. Esse é o caso do córrego do Sossego e seus afluentes, que são a referência reconhecida com a qual íamos a campo e conseguíamos conversar com os moradores. Mas, para além dessa referência inicial, os mapas dos moradores não coincidiam com o dos cartógrafos. $\mathrm{O}$ processo de mapeamento 
como um todo é mais eivado de subjetividade que se possa supor, pois resulta de escolhas: de recorte, de escala, de projeção, de métrica5

Inserida no amplo conjunto de imagens socialmente inventadas, a particularidade do mapa talvez resida na visão de cima ou visão vertical. Visão artificial e deificadora. Ortovisão: possibilidade de ver todos os pontos ao mesmo tempo. Visão onipresente.

Se o desejo costuma incidir justamente naquilo que nos falta, não seria a visão na qual o mapa é especializado que moveria o desejo humano por mapas? Em outras palavras, o mapa oferece-nos uma forma de ver e, com isso, realiza o (nosso, humano) desejo de ver como um deus veria: tudo ao mesmo tempo. A questão é menos simples do que parece, porque o objeto mapa seduz pelo que pretende representar: o território, o lugar. Mas, ao fazer isso, apresenta uma outra coisa: uma versão de território ou de lugar desprovida de vida, porque estável.

A estabilidade do território e do lugar garantida pelo mapa, como ensina Massey (2008), serve como conjunto de referências usáveis em várias dimensões da vida prática ou lúdica. Assim, sendo portador de referências usáveis, reconhecíveis pela experiência comum, os mapas são lidos como verdade, como natureza do território ou do lugar. A localização e os atributos dos objetos, fatos ou fenômenos, e o recorte da área, transformam-se nos fios que tecem um discurso territorial. Esse é o poder do mapa.

A naturalização é a principal competência do discurso do mapa, é o parâmetro para imposição de sua verdade. Daí por que o desejo do mapa é ser tomado como a prova de que algo existe daquela forma que ali está grafada. Todo mapa deseja que olhemos seus signos não como algo grafado numa superfície, mas como a própria superfície manifestada diante de nós. Em seu modo particular de arranjar sinais gráficos, aos quais se atribuem significados sobre uma superfície plana, o mapa, em verdade, dá existência para aquilo que quer "representar": o espaço como uma superfície lisa onde se distribuem fenômenos simultâneos e integrados num único sistema, numa única história (natural e social). Mesmo os mapas da chamada Nova Cartografia Social ${ }^{6}$, um projeto de alta relevância para dar visibilidade à territorialidade de populações locais, operam nessa lógica.

Mas, para além das possibilidades de desvelamento desse discurso a partir do seu próprio universo sígnico, há a questão de que, na sua construção

5. Sobre essa discussão, ver Fonseca (2007), cuja autora analisa o uso da métrica cartesiana como dado e não como escolha.

6. O Projeto Nova Cartografia Social realiza oficinas de elaboração de mapas por comunidades locais, visando empoderá-las dessa técnica para que o mapa realizado pelas comunidades seja um instrumento de luta por territórios. Ver: Acselrad, H.; Coli, I. Disputas Cartográficas e Disputas Territoriais. In: Acselrad (2008) e www.novacartografiasocial.com. 
locacional, o mapa impõe um modo específico de pensar o espaço como se este fosse composto de estabilidades e sincronias (Massey, 2008).

Esse objeto, o mapa, que simula uma imagem de território estável, capturável no todo (porque visto na ortovisão) e em toda sua natureza, cada vez mais disponível pela disseminação tecnológica e cada vez mais produzido porque é, ele mesmo, elemento da reprodução do capital, vira objeto de desejo e, nesse ganho de autonomia, de coisa desejada, de fetiche, por sua vez, deseja-nos.

\section{Imagem cartográfica e produção de mundos, de geografia e de pensamentos sobre o espaço}

O que o mapa das artes, o GPS do taxista, o mapa do Sossego e o mapa do Atlas escolar inspiram de reflexão sobre imagem e produção de geografias? Analisemos cada um:

O mapa das artes guia-nos no universo cultural de São Paulo. Que universo cultural? Que São Paulo? A São Paulo compreendida como o centro expandido, no qual quem circula também consome o que seus patrocinadores oferecem: tintas, telas, molduras, exposições... Se a concentração dos loci de emergência da arte em São Paulo pode ter uma explicação na história, na diacronia, a sincronia afirmada por aquele mapa transporta o significado para um outro universo.

A maior latência desse discurso territorial sobre a arte é a exclusão da periferia. O mapa não acessa esse conteúdo social, exclui-o, e ao fazer isso define seu público, além de agir, subrepticiamente, no estabelecimento do que é o lugar denominado São Paulo. Não é uma intenção explícita, é uma quase naturalidade que o mapa traduz, por sua linguagem própria: por sua escala, por seus signos, por ser um símbolo. Assim, a geografia da arte em São Paulo tem seu público, suas referências diacrônicas, sua territorialidade capturada pela sincronia. Um monumento histórico que fale da fundação da cidade ou um elemento que signifique sua inserção no sistema mundo estão no mesmo nível visual que as galerias privadas.

O mapa dá existência e força a um circuito que a própria Arte se esforça em romper, quando aparece nomeada em alguma ação ou obra cuja aparição se deu fora dos limites do mapa, ou seja, na periferia, naquilo que não é (mais) São Paulo. Essa forma de captura da imaginação pelo mapa é também produto dos próprios artistas que buscam, muitas vezes, distinguir o que é a Arte, com letra maiúscula, e o que é arte popular ou coisa que valha. Este mapa das artes não é obra apenas do capital e do mercado (o que fica nítido pela moldura feita de mercadorias), mas é também da tradição discriminatória de muitos artistas e curadores brasileiros. 
O mapa do GPS de navegação do taxista deixa aflorar, na sua persistência, a transferência de valores humanos presentes nas relaçôes sociais para alguma coisa que esteja fora dela. A tecnologia avaliza a honestidade do taxista, uma vez que esta última foi perdida ao longo da história dos táxis e taxistas nas grandes cidades brasileiras. Aprendemos a desconfiar das palavras dos taxistas e de seus itinerários e então alguns taxistas recorrem ao mapa como garantia. Uma garantia, uma honestidade, deslocada do corpo e da palavra e localizada num objeto externo ao taxista; este deseja que o mapa prove sua honestidade.

É claro que as geotecnologias têm seu papel na otimização dos deslocamentos. A logística é o principal motor de seu desenvolvimento porque transmuta o território em componente da produção. Assim, o GPS em táxis cumpre seu papel de apontar o melhor caminho (leia-se, o mais rápido) dentro do paradigma da compressão espaço-tempo na metrópole.

Também aqui há uma transferência: a da mediação das relações sociais. Não há história, não há a vivência/experiência da paisagem e dos problemas da metrópole. A tecnologia baliza o possível. Entre o ponto de partida e o ponto de chegada, dois fragmentos, há mais o tempo que o espaço. A duração do trajeto, que está no próprio trajeto em seus desdobramentos de tráfego, no desenho urbano, é inquestionável, porque ancorada num poder maior que é o da informação, materializada nos aparelhos tecnológicos.

Sem dúvida, um instrumento útil. E também, sem dúvida, um ícone dos tempos em que vivemos, em que o conhecimento das pessoas (mesmo o dos especialistas) está sendo deslocado para os exames feitos por aparelhos que perscrutam e provam a existência de algo que estaria para além, não da visão, mas do conhecimento humano.

O mapa do Sossego é exemplar do descolamento que há entre a captura do território pela oficialidade para seu domínio e a construção cotidiana dos territórios, o espaço banal, o espaço que, conforme Massey (2008), não é só aqui, mas também agora. A territorialidade construída pela história das famílias e seus modos de apropriação da natureza, sua organização social, é ausente no mapa topográfico. Pelo menos, parcialmente ausente.

O oficial, como sinônimo do certo, tem um peso tal que leva o indivíduo a negar suas próprias referências de vida, de história, de relações sociais. É, sem dúvida, um sistema de significações com forte presença, mas pronto para ser classificado como errado, já que difere do oficial, sendo este oficial aquele grafado no mapa. Dito de outra forma, o mapa deseja ser visto como o oficial, e o oficial deseja ser visto como o mapa (Oliveira Júnior, 2009).

Se limitações técnicas (a escala, a reambulação, etc.) foram, na origem, responsáveis por essas ausências em prol de uma padronização nacional, o uso local - pela prefeitura, pelos correios - indica uma articulação mais ampla das 
redes de controle do território, na busca do apagamento de tudo aquilo que manifesta o tempo e as relações como constituintes do espaço, tanto quanto as distâncias e as localizaçôes. Ao apagar as relações sociais, a presença mesma de pessoas, no espaço, os mapas solicitam aos seus usuários - neste caso, eu mesma e os demais pesquisadores do projeto - que não se pautem pelas indicações de quem encontrar nos locais, mas nos instrumentos que a ciência e a tecnologia as mesmas que produziram o mapa - colocaram e colocam à disposição para observar e usar o espaço, da bússola ao GPS.

O mapa do Atlas escolar assemelha-se, em partes, ao do exemplo anterior, diferindo no fato de ser um produto comercial, mas que vira "oficial" na medida em que reside numa biblioteca de escola pública. Ao questionar a ausência da sua cidade no mapa, alunos e professora apontam o fato de os critérios técnicos serem também critérios políticos. Escolhem as maiores cidades e as tornam ainda mais influentes aos olhos daqueles que se habituam a tomá-las como parâmetro de localização e importância.

Marcar e escrever o nome da cidade no mapa seria mesmo um dano ao patrimônio público? Seria esse o limite entre o "consumível" e o não "consumível", escrito nos materiais didáticos presentes nas escolas? Consumível é aquele material em que podemos grafar nosso lugar no planeta e é também aquele material que pode ser jogado fora ao final de cada ano. E o não consumível é aquilo que deve permanecer intocado para sempre, como um "documento", sem outras marcas de importância que não as autorizadas por aqueles que tiveram o poder de imprimi-los. Que autonomia se pode ter para reescrever um "documento"? Lembra-me isso a cena do filme "Sociedade dos poetas mortos", em que o professor instrui seus alunos a arrancarem páginas do livro que não lhes fariam sentidos dentro daquele modo de se relacionar com a produção literária. Neste caso, grafar no mapa a cidade ausente seria dar mais sentido, maior importância, intensidade, àquilo que era somente um documento de acervo.

\section{Para terminar}

Tivemos, neste texto, a intenção de tentar inverter o olhar, já sedimentado de produção geográfica sobre imagens cartográficas, que se pauta nas palavraschave comunicação, técnica/tecnologia, representação do território. O deslocamento para os sentidos que o mapa ganha quando se autonomiza e circula faz emergir uma produção de pensamento sobre o espaço e, em muitas situações, apagamentos. Apagamentos de partes da geografia real, de dimensóes de vidas em produção e em relação.

Como afirmam Crampton e Krygier (2006, p.15): "Mapas são ativos: eles constroem conhecimento ativamente, eles exercitam poder e eles podem ser 
meios poderosos de promoção de mudanças sociais". Resta entender de que natureza são essas mudanças. Neste artigo pretendemos dar visibilidade ao fato de que a imagem cartográfica disseminada e entranhada na vida social produz mundos e capturam-nos para eles. São desejantes neste sentido. Esta questão é pauta de primeira ordem para a Cartografia Geográfica, para o entendimento do significado e do sentido da Cartografia na Geografia e em seu ensino.

\section{Referências bibliográficas}

ACSELRAD, Henri (Org.). Cartografias sociais e território. Rio de Janeiro: IPPUR/UFRJ, 2008. $167 \mathrm{p}$.

COSTA, Rogério Haesbaert da. O mito da desterritorialização: do "fim dos territórios" à multiterritorialidade. 2. ed. Rio de Janeiro : Bertrand Brasil, 2006. 400 p.

CRAMPTON, Jeremy. W.; KRYGIER, John. An introduction to critical cartography. ACME: An international e-journal for critical geographies, v. 4, n.1, p.11-33, 2006.

FONSECA, Fernanda Padovesi da. O potencial analógico dos mapas. Boletim Paulista de Geografia, São Paulo, n. 87, p. 85-110, dez./2007.

GIRARDI, Gisele. A cartografia na geografia brasileira a partir dos anos 1970: notas para a compreensão de uma situação ainda a ser superada. In: CONGRESSO BRASILEIRO DE GEÓGRAFOS, 6., 2004, Goiânia. Anais... Goiânia : AGB, 2004. CD-ROM.

HARLEY, J. Brian. A nova história da cartografia. O Correio da Unesco, São Paulo, v. 19, n. 8, p. 4-9, 1991.

KOLACNY, Antonin. Cartographic information: concepts and terms in modern cartography. Cartographica - the nature of cartographic communication, Toronto, n. 21, p. 39-45, 1977.

MASSEY, Doreen. Pelo Espaço: uma nova política da espacialidade. Rio de Janeiro: Bertrand, 2008. $312 \mathrm{p}$.

MORAES, Antonio Carlos Robert. Geografia: pequena história crítica. 15. ed. São Paulo : Hucitec, 1997. $130 \mathrm{p}$.

MOREIRA, Ruy. O círculo e a espiral. Niterói: Ed. AGB Niterói, 2004. 192 p.

OLIVEIRA JÚNIOR, Wencesláo Machado de. Apontamentos sobre a educação visual dos mapas: a (des)natureza da ideia de representação In: COLÓQUIO DE CARTOGRAFIA PARA CRIANÇAS E ESCOLARES, 6., 2009, Juiz de Fora. Anais... Juiz de Fora : UFJF, 2009. CD-ROM.

Recebido em 31 de outubro de 2008 e aprovado em 06 de março de 2009.

Agradecimento: Agradeço a Wenceslao Machado de Oliveira Jr pela cuidadosa leitura da primeira versão e pelas valiosas contribuições a este texto. 